\title{
VALORAÇÃO ECONÔMICA DA ÁREA DE PROTEÇÃO AMBIENTAL ESTADUAL DA CACHOEIRA DAS ANDORINHAS - MG ${ }^{1}$
}

\author{
Vanessa Cotta Silveira ${ }^{2}$, Jader Fernandes Cirino ${ }^{3}$ e José Francisco do Prado Filho ${ }^{4}$
}

\begin{abstract}
RESUMO - A valoração econômica dos ativos ambientais é importante critério que subsidia a tomada de decisões na definição de políticas que gerenciam os recursos naturais. Nesse sentido, buscou-se valorar a Área de Proteção Ambiental Estadual da Cachoeira das Andorinhas (APAE/CA), importante Unidade de Conservação do Município de Ouro Preto, MG, com 18.700 ha de extensão. Apesar de possuir importante patrimônio natural, tal ativo ambiental possui áreas degradadas, além de ainda não ter o respaldo necessário dos órgãos gestores para o seu efetivo manejo. Como área de estudo, definiu-se a sub-bacia do Rio das Velhas, na qual a APAE/CA está inserida, abrangendo distritos localizados em Ouro Preto e Itabirito. Utilizando a Valoração Contingente, através da abordagem de Hanemann (1984) e do método do bootstrapping, obteve-se a disposição a pagar (DAP) mensal mediana por habitante dos distritos envolvidos pela melhoria e preservação da APAE/CA de R $\$ 15,43$. $\mathrm{O}$ valor econômico calculado para o ativo ambiental foi de $\mathrm{R} \$ 10.398 .030,12$, representando os benefícios anuais fornecidos pela APAE/CA e que são percebidos pelos entrevistados. Conjuntamente com a valoração, utilizaram-se variáveis de percepção ambiental, a fim de verificar seu impacto sobre a DAP em estudo. Os resultados encontrados apontaram que a percepção e a valoração ambiental são positivamente correlacionadas.
\end{abstract}

Palavras-chave: APA Estadual da Cachoeira das Andorinhas, Método de Valoração Contingente, Disposição a Pagar.

\section{ECONOMIC VALUATION OF THE STATE ENVIRONMENTAL PROTECTION AREA OF CACHOEIRA DAS ANDORINHAS - MG}

\begin{abstract}
The economic valuation of environmental assets is an important criterion that subsidizes the decision-making in the policies definition that manage natural resources. Therefore, it was aimed to valuing the Área de Proteção Ambiental Estadual da Cachoeira das Andorinhas (APAE/CA - State Environmental Protection Area of Cachoeira das Andorinhas), an important Conservation Unit in Ouro Preto, Minas Gerais State, with 18,700 hectares of extension. Despite having an important natural heritage, such environmental asset has degraded areas in addition to the lack of the necessary supporting by the management organs for its effective use. As a study area, the Rio das Velhas sub-basin was defined, where APAE/CA is inserted, covering districts located in Ouro Preto and Itabirito municipalities. By using the Contingent Valuation, through the approach of Hanemann (1984) and the bootstrapping method, it was achieved the monthly meadian willingness to pay (DPA) per capita of the districts involved in the improvement and preservation of APAE/CA of R \$15.43. The economic value calculated for the environmental asset was $R \$ 10,398,030.12$, representing the annuals benefits provided by APAE/CA which are noticed by the interviewed people. Environmental perception variables were used together with the evaluation, in order to verify its impact on DAP under study. The results pointed that the perception and the environmental valuation are positively correlated.
\end{abstract}

Keywords: State Environmental Protection Area of Cachoeira das Andorinhas, Contingent Valuation Method, Willingness to Pay.

\footnotetext{
${ }^{1}$ Recebido em 23.01.2012aceito para publicação em 09.04.2013.

${ }^{2}$ Programa de Pós-Graduação em Engenharia Ambiental na Universidade Federal de Ouro Preto, UFOP, Brasil. E-mail:<vanessacotta@yahoo.com.br>.

${ }^{3}$ Departamento de Economia Universidade Federal de Viçosa, UFV, Brasil. E-mail:<jader.cirino@ufv.br>.

${ }^{4}$ Departamento de Engenharia Ambiental, Universidade Federal de Ouro Preto. E-mail:<jfprado@ depro.em.ufop.br>.
} 


\section{INTRODUÇÃO}

Após a Revolução Industrial, o homem intensificou de forma significativa a interferência no meio ambiente. Os impactos ambientais provocados pelo crescimento da população, pelas atividades industriais, pelo consumo e pela utilização de recursos naturais têm provocado danos consideráveis aos ecossistemas na forma de diminuição dos ativos ambientais disponíveis, geração crescente de resíduos, mudanças climáticas e catástrofes ambientais, entre outros.

Diante desse panorama, coloca-se como fundamental o termo desenvolvimento sustentável, usado originalmente em WCED (1987). Tal conceito pode ser entendido como um processo de crescimento econômico no qual a elevação da renda é acompanhada não apenas por melhoria no aspecto político e social, mas também por melhoria e conservação ambientais. Em outras palavras, o desenvolvimento sustentável é uma nova forma de organização econômica e social na qual a utilização dos recursos naturais é feita buscando-se atender aos anseios e aspirações do presente sem, no entanto, comprometer a qualidade de vida das gerações futuras. Nesse sentido, torna-se importante a elaboração de políticas públicas voltadas para a utilização sustentável de tais recursos.

Nesse contexto, o objetivo deste trabalho consistiu na valoração econômica da Área de Preservação Ambiental Estadual da Cachoeira das Andorinhas (APAE/ CA), por meio da disposição a pagar (DAP) dos indivíduos beneficiados pelos serviços ambientais que o referido ativo natural fornece.

Sobre a valoração de Unidades de Conservação, Sousa e Mota (2006) destacaram que, considerando os benefícios socioambientais que os ativos naturais fornecem, trabalhos de valoração econômica para quantificá-los são importantes. Isso porque tais estudos podem subsidiar o processo de gestão das políticas públicas ambientais destinadas à preservação e à gestão sustentável de tais ativos. Sobre esse aspecto, a estimativa de valores econômicos para os serviços ambientais poderia ser utilizada em análises de custobenefício de tais políticas, o que permitiria que o governo tivesse condições de avaliar se determinada política seria eficiente no sentido de aumentar o bem-estar da sociedade, devendo, portanto, nessas circunstâncias, ser implementada. Cirino e Lima (2008) afirmaram que a valoração poderia ser utilizada na avaliação da viabilidade econômica de projetos públicos ou privados voltados para a exploração sustentável da potencialidade do ecoturismo da região. Pearce (1992) enfatizou que a valoração auxilia na consecução do desenvolvimento sustentável, uma vez que o ser humano tende a usar, de maneira racional, somente aquilo que apresenta valor monetário positivo.

Adicionalmente, neste trabalho procurou-se relacionar a valoração com a percepção ambiental. $\mathrm{O}$ estudo da percepção ambiental é relevante para a melhor compreensão das inter-relações entre o homem e o ambiente, suas expectativas, suas satisfações e insatisfações, julgamentos e condutas (PACHECO; SILVA, 2007). Destaca-se que a associação entre percepção e valoração ambiental tem sido pouco explorada na literatura.

O objetivo geral da pesquisa foi, dessa forma, obter um valor econômico para a APAE/CA, por meio da disposição a pagar, dos indivíduos, pelo fluxo de serviços ambientais que o referido bem fornece. Especificamente, procurou-se: a) levantar as características socioeconômicas da população de interesse, assim como sua forma de relacionamento com a APAE/CA; b) estimar a disposição a pagar, dos indivíduos, para melhorar e, posteriormente, conservar a qualidade ambiental do ativo em estudo; e c) identificar os fatores que mais afetam a valoração da APAE/CA.

\section{MATERIAL E MÉTODOS}

\subsection{Caracterização da área de estudo}

A Área de Proteção Ambiental Estadual da Cachoeira das Andorinhas (APAE/CA) foi criada pelo Decreto Estadual n $n^{\circ} 30.264$, de 16 de outubro de 1989, com alteração de dispositivos pelo Decreto Estadual $n^{\circ} 42.912$, de 26 de setembro de 2002. É gerenciada atualmente pelo Instituto Estadual de Florestas de Minas Gerias (IEF).

AAPAE em estudo possui uma área de 18.700 ha e está situada na região Nordeste do Município de Ouro Preto, abrangendo todo o Distrito de São Bartolomeu e parte do bairro Morro de São Sebastião, no distrito-sede. Insere-se na vertente Norte da Serra de Ouro Preto, cuja vertente sul, tombada pelo Instituto do Patrimônio Histórico e Artístico Nacional (IPHAN), emoldura o entorno histórico da cidade, patrimônio mundial da humanidade. 
A Cachoeira das Andorinhas encontra-se inserida em áreas designadas como prioritárias para a conservação da biodiversidade brasileira, considerada de "importância biológica extrema" para o bioma da Mata Atlântica e para a conservação da biodiversidade de Minas Gerais (IEF/UFV, 2005). No entanto, conforme destacaram Scalco (2009) e Rezende et al. (2011), a efetiva preservação e utilização sustentável do referido ativo tem encontrado como entraves a falta de pessoal capacitado para atuar na área e de um plano de manejo, o que faz que apresente interiormente áreas degradadas. Uma vez que essa APAE apresenta importante diversidade biológica e carece de políticas e investimentos públicos para a melhor preservação e uso sustentável, justifica-se sua valoração econômica como forma de subsidiar a adoção de medidas que possam solucionar as deficiências citadas na sua conservação ${ }^{5}$.

\subsection{Modelo analítico utilizado}

Um dos métodos mais utilizados na economia ambiental para valoração econômica do meio ambiente é a valoração contingente, que procura mensurar monetariamente o nível de bem-estar dos indivíduos decorrente de uma variação na quantidade ou qualidade ambiental de um recurso natural. Nesse método são feitas pesquisas amostrais com a finalidade de identificar as preferências de uma pessoa com relação a bens que não são comercializados no mercado comum. A vantagem desse método é poder valorar bens públicos e ambientais, visto que estes têm como característica a ausência de um mercado formal, ou seja, são considerados bens não transacionáveis no mercado real. Além disso, é o único método capaz de captar o valor de existência de um bem, já que este valor não se revela por complementaridade ou por substituição de um bem privado (MOTTA, 2006). O Método da Valoração Contingente (MVC), conforme destacaram Silva e Lima (2004), apresenta-se muito bem estruturado pela teoria econômica, tendo como referencial a teoria microeconômica do consumidor e do bem-estar. A fim de minimizar a presença de vieses nos resultados da pesquisa, procurou-se desenvolver um mercado hipotético próximo da realidade, utilizando a Disponibilidade a Pagar (DAP) e uma técnica de obtenção discreta. Também, procurou-se esclarecer os entrevistados sobre a forma de pagamento para conservação e melhoria do ativo ambiental, a fim de desenvolver formulário que minimizasse respostas estratégicas, incoerentes ou tendenciosas ${ }^{6}$.

Utilizou-se a técnica conhecida como referendo simples para obter os indicadores discretos da DAP, a partir da abordagem de Hanemann (1984), que parte da estimativa de um modelo logit, conforme Sellar et al. (1986), assumindo a seguinte estrutura neste estudo:

$L_{j}=\beta_{1}+\beta_{2} D_{A P}+\beta_{3} R_{p p c}+\beta_{4} S_{j}+\beta_{5} I_{j}+\beta_{6} E_{j}+\beta_{7} D 1_{j}$ $+\beta_{8} \mathrm{D} 2_{\mathrm{j}}+\beta_{9} \mathrm{D} 3_{\mathrm{j}}+\beta_{10} \mathrm{D} 4_{\mathrm{j}}+\beta_{11} \mathrm{D} 5_{\mathrm{j}}+\beta_{12} \mathrm{D} 6_{\mathrm{j}}+\beta_{13} \mathrm{D} 7_{\mathrm{j}}$ $+\beta_{14} \mathrm{C} 1_{j}+\beta_{15} \mathrm{C} 2_{j}+\beta_{16} \mathrm{C} 3_{j}+\beta_{17} \mathrm{C} 4_{j}+\beta_{18} \mathrm{C} 5_{j}+$

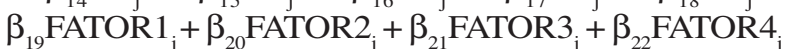
$+\beta_{23}$ FATOR $_{j}+{ }^{a}{ }_{j}$

em que $\mathrm{Lj}=$ o logit do indivíduo j obtido a partir da variável dicotômica $Y_{j}$, que assume o valor 1 quando o entrevistado aceita o pagamento proposto para melhorar e, posteriormente, conservar a qualidade ambiental da APAE/CA e 0 em caso contrário; bi ( $\mathrm{i}=1$ a 23) = os parâmetros a serem estimados; DAPp $=$ o valor proposto ao entrevistado, visando à conservação e melhoria ambiental da APAE/CA; RFpc = renda familiar per capita em reais, obtida dividindo-se a renda da família pelo número de membros; $\mathrm{S}=$ uma variável dummy: 1 - homem, 0 - mulher; I é idade em anos do respondente; $\mathrm{E}=\mathrm{o}$ tempo de escolaridade do entrevistado; $\mathrm{D}_{1}$ $(1=1$ a 7$)=$ variáveis dummies que indicam o distrito do entrevistado, com o grupo-base representando o distrito-sede $; \mathrm{D}_{1}=$ Glaura $; \mathrm{D}_{2}=$ São Bartolomeu; $\mathrm{D}_{3}$ $=$ Cachoeira do Campo; $\mathrm{D}_{4}=$ Rodrigo Silva; $\mathrm{D}_{5}=$ Amarantina; $\mathrm{D}_{6}=$ Santo Antônio do Leite; $\mathrm{D}_{7}=$ Acuruí e São Gonçalo do Monte - Distritos de Itabirito; C1= uma dummy, que assume o valor 1 se o entrevistado sabe o que é uma Unidade de Conservação e 0 em caso contrário; $\mathrm{C} 2$ = dummy que assume o valor 1 se o entrevistado conhece alguma Unidade de Conservação no município onde reside e 0 em caso contrário; C3 = dummy que assume o valor 1 se o entrevistado já ouviu falar na APAE/CA e 0 em caso contrário; $\mathrm{C} 4$ = dummy que indica se o entrevistado já visitou alguma vez a APAE/CA, assumindo o valor 1 para sim e 0 em caso contrário; $\mathrm{C} 5=$ dummy que assume o valor 1 se o entrevistado acredita que suas atitudes podem afetar ou influenciar de alguma forma a APAE/CA; FATOR ${ }_{m}$

\footnotetext{
${ }^{5}$ Para uma caracterização mais detalhada da APA/CA, consultar Silveira (2011).

${ }^{6} \mathrm{O}$ formulário na íntegra pode ser obtido em Silveira (2011), disponível em: <http://www.proamb.ufop.br/defesas/123.pdf>.
}

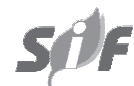

Revista Árvore, Viçosa-MG, v.37, n.2, p.257-266, 2013 
$(\mathrm{m}=1$ a 5$)=$ as variáveis de percepção ambiental, cuja obtenção e descrição serão detalhadas adiante na metodologia; e $\epsilon=$ erro aleatório.

Ressalta-se que a escolha de tais variáveis foi feita com base em estudos de valoração ambiental que utilizaram o MVC em contexto similar ao deste trabalho, como os de Silva e Lima (2004), Cirino e Lima (2008) e Brugnaro (2010). Foram acrescentadas variáveis específicas relacionadas à APAE/CA, como as variáveis de distrito e aquelas referentes à percepção ambiental $\operatorname{FATOR}_{1}(1=1$ a 5$)$.

As variáveis de percepção ambiental foram obtidas a partir de 26 questões relacionadas a esse tema no formulário disponível em Silveira (2011). Seguindo a metodologia proposta por Cantagallo e Kuwahara (2009), para cada questão cujo conteúdo estava relacionado com atitudes individuais consideradas de compromisso ambiental, o respondente atribuiu valor de 1 a 5 , e seu grau de percepção ambiental em cada questão estava expresso nesse intervalo. O valor 5 indicava alta percepção sobre o que foi questionado e o valor 1 , baixa percepção sobre o parâmetro ambiental.

A fim de agrupar essas 26 questões em um número menor de variáveis visando à sua incorporação ao modelo (1), utilizou-se a técnica de análise fatorial, que tem como objetivo descrever a estrutura de dependência de um conjunto de variáveis que supostamente medem aspectos comuns. Agregando essas variáveis, tenta-se substituí-las por um número menor de fatores que expliquem o fenômeno de interesse, que, neste trabalho, é a percepção ambiental dos habitantes da área de influência da APAE/CA.

Conforme Hair et al. (1998), no modelo de análise fatorial cada uma das variáveis é definida como uma combinação linear dos fatores comuns que irão explicar a parcela da variância de cada variável, mais um desvio que resume a parcela da variância total não explicada por esses fatores. A parcela explicada dos fatores comuns recebe o nome de "comunalidade", e a parcela não explicada é chamada de "especificidade". As comunalidades podem variar de 0 a 1 . Os valores próximos de 0 indicam que os fatores comuns não explicam a variância, e aqueles próximos de 1 significam que todas as variâncias são explicadas pelos fatores comuns.
Neste trabalho, associam-se aos fatores comuns as variáveis relacionadas às questões de percepção ambiental do indivíduo.

Quanto ao método de obtenção dos fatores, optou-se por utilizar o dos componentes principais, que explica a estrutura da variância e da covariância através de poucas combinações lineares das variáveis originais (HAIR et al., 1998).

Uma ferramenta importante na interpretação dos fatores obtidos com a análise fatorial é a sua rotação, que pode ser ortogonal ou oblíqua. De acordo com Hoffmann (1999), o objetivo da rotação ortogonal é facilitar a interpretação dos fatores, pois cada um dos novos fatores, após a rotação, deve apresentar uma correlação relativamente forte com uma ou mais variáveis e correlação relativamente fraca com as demais variáveis. Segundo Hair et al. (1998), entre os métodos de rotação ortogonal se destaca o Varimax (Kaiser on), utilizado neste estudo. Esse método é o mais comumente utilizado e minimiza o número de variáveis com altas cargas sobre o fator, reforçando a interpretabilidade dos fatores.

Retomando o modelo (1) e a abordagem de Hanemann (1984), observou-se que, em uma amostra qualquer, tal metodologia fornece apenas uma estimativa para a DAP verdadeira. Para obter uma distribuição de tal medida para que se tenha um valor médio e mediano da DAP verdadeira, utilizou-se o método conhecido como bootstrapping ${ }^{7}$. Este parte inicialmente da estimação do modelo (1) e sua substituição na Função de Distribuição Acumulada Logística, gerando um vetor inicial de resíduos estimados. Somando aleatoriamente esses últimos com as probabilidades estimadas para a aceitação da valoração contingente, obtém-se uma nova série para a variável dependente binária $\mathrm{Y}_{\mathrm{j}}$, que dá origem ao modelo logit (1).

Repetindo t vezes o referido procedimento, tem-se um conjunto diferente de $t$ variáveis aleatórias distintas $\mathrm{e}$, consequentemente, $\mathrm{t}$ vetores de parâmetros $\beta$. Esses últimos fornecerão t DAPs verdadeiras, que poderão ser usadas para formar uma distribuição probabilística dessa medida, cujas medidas de tendência central poderão ser utilizadas para se obter a DAP verdadeira referente à APAE/CA para a população de interesse.

${ }^{7}$ Mais detalhes sobre esse método podem ser obtidos em Silva e Lima (2004) e Cirino e Lima (2008).

Revista Árvore, Viçosa-MG, v.37, n.2, p.257-266, 2013 


\subsection{A base de dados para o cálculo do MVC}

Quanto à base de dados, é importante ressaltar que, quando se realiza uma pesquisa de MVC, procura-se determinar uma população natural que seja a mais adequada para valorar um bem público com localização definida. Geralmente, esse termo natural é definido em termos políticogeográficos. Dessa forma, escolheu-se como área de influência do estudo a sub-bacia do Alto Rio das Velhas, compreendendo os Distritos de Ouro Preto e Itabirito, que possuem relação com a APAE/CA.

De acordo com dados do IBGE (2007), os distritos selecionados abrangiam 56.157 habitantes. Utilizando a fórmula estatística padrão para o cálculo de amostra de população finita (GIL, 2002), com nível de confiança de $95 \%$ e erros amostrais médios por distrito de $10,2 \%$, propôs-se a aplicação de 723 formulários. A condução das entrevistas foi feita pelo Núcleo de Estudos Aplicados e Sociopolíticos Comparados da Universidade Federal de Ouro Preto (NEASPOC/UFOP), entre os meses de outubro e dezembro de $2010^{8}$.

O formulário utilizado na pesquisa foi composto por quatro partes. A primeira com questões sobre variáveis socioeconômicas relativas aos entrevistados. A segunda abordando questões que buscavam analisar o sentimento dos amostrados para com o meio ambiente e o ativo ambiental em estudo, dando origem às variáveis de percepção ambiental. A terceira continha questões que buscaram compreender qual o conhecimento dos entrevistados a respeito da APAE/CA. Por fim, a quarta parte foi composta por uma descrição geral do objeto de pesquisa e teve como objetivo principal estimar a DAP dos entrevistados pela manutenção e conservação do fluxo de funções e serviços ecossistêmicos que o ativo ambiental promove. Como forma de obtenção da DAP verdadeira, foi escolhido o método de referendo simples, no qual o entrevistado responde sim ou não, caso concorde ou discorde do pagamento por um valor proposto. O questionário apresentou a seguinte questão: "você estaria disposto a pagar $\mathrm{R} \$ \mathrm{X}$ na forma de um boleto bancário, a ser pago mensalmente, a fim de se criar um fundo de recursos para conservar e melhorar a qualidade ambiental da APA Estadual Cachoeira das Andorinhas?".
A quantia X que representa a DAPp no modelo (1) foi modificada de maneira aleatória ao longo da amostra para se avaliar a frequência das respostas dadas diante de diferentes níveis de lances. Os referidos valores foram obtidos a partir de procedimento sugerido por Silva e Lima (2004) baseado na Técnica Delphi, que consiste em enviar questionários a um grupo de especialistas sobre determinado assunto, a fim de que eles entrem em um consenso confiável acerca da formação de cenário ou da previsão de tendências. Neste trabalho foram consultados 15 especialistas, que determinaram os seguintes valores para a DAPp: $\mathrm{R} \$ 1,40 ; \mathrm{R} \$ 3,60$; $\mathrm{R} \$ 6,70 ; \mathrm{R} \$ 9,20 ; \mathrm{R} \$ 12,50 ; \mathrm{R} \$ 15,00 ; \mathrm{R} \$ 18,80 ; \mathrm{R} \$ 20,70 ;$ e $R \$ 31,60$. Entre os especialistas consultados ${ }^{9}$, havia doutores ou mestres com experiência em trabalhos de valoração ambiental e, ou, ligados diretamente à problemática ambiental, assim como pessoas ligadas diretamente às questões de gestão e preservação relativas à APAE/CA. Nesse último grupo, foram ouvidos o gerente da APAE/CA e o gerente da unidade de conservação da Floresta Uaimií, incluída no referido ativo natural, servidores da Prefeitura de Ouro Preto responsáveis por questões ambientais do município e representantes de ONGs relacionadas a questões ambientais atuantes na área de interesse deste estudo.

\section{RESULTADOS}

\subsection{Características descritivas e socioeconômicas da amostra}

Entre as 723 pessoas entrevistadas, 49,65\% eram mulheres e 50,35\% homens. Quanto à idade, observou-se número maior de entrevistados na faixa de 25 a 34 anos $(22,54 \%)$, seguido pela faixa de 45 a 59 anos $(21,85 \%)$. Ainda quanto à idade, observou-se que as faixas de menor ocorrência dos entrevistados foram de 16 e 17 anos $(4,70 \%)$ e pessoas com mais de 60 anos $(15,21 \%)$.

Em relação ao nível de escolaridade dos entrevistados, a maioria possuía nível educacional secundário completo, totalizando $31,54 \%$ do total da amostra. Observou-se que $2,49 \%$ dos respondentes eram analfabetos; $7,19 \%$ tinham até a $4^{\mathrm{a}}$ série incompleta; $14,66 \%$ possuíam até a $4^{\mathrm{a}}$ série completa; $13,14 \%$ tinham da $5^{\mathrm{a}}$ à $9^{\mathrm{a}}$ série incompleta; $7,61 \%$ possuíam o $1^{\circ} \mathrm{grau}$

\footnotetext{
${ }^{8}$ As questões utilizadas no formulário assim como maiores detalhes acerca da pesquisa de campo realizada podem ser obtidos em Silveira (2011).

${ }^{9}$ A lista completa dos especialistas está disponível em Silveira (2011).
} 
completo; $11,48 \%$ tinham o segundo grau incompleto; $5,95 \%$ possuíam o universitário incompleto; e 9,8\% tinham curso superior completo ou mais.

Com relação à renda pessoal mensal dos entrevistados, a maioria das pessoas (34\%) recebia entre um e dois salários mínimos $(\mathrm{R} \$ 510,00$ era o valor do salário mínimo vigente na época da pesquisa), seguidos pelos que não tiveram renda (16,9\%). Destaca-se que $12,6 \%$ dos entrevistados não responderam ou não sabiam a resposta da pergunta. A média da renda mensal dos entrevistados que responderam à questão (632 pessoas) foi de R\$906,00. Quando analisada a renda familiar, verificou-se que a faixa de $\mathrm{R} \$ 510,00$ a R $\$ 1.020,00(22,82 \%)$, da mesma forma que a renda pessoal, predominava. As faixas de $\mathrm{R} \$ 1.020,00 \mathrm{aR} \$ 1.530,00(20,19 \%) \mathrm{e} \mathrm{R} \$ 1.530,00$ a $\mathrm{R} \$ 2.550,00(16,60 \%)$ também tiveram considerável importância. A média da renda familiar mensal foi de $\mathrm{R} \$ 1.771,60$ para aqueles que responderam à questão (571 pessoas). Dessa forma, quanto à variável renda, a principal conclusão é de que as pessoas da área de influência da APAE/CA possuem renda mensal bastante variada, com predomínio de renda baixa (classes E e $\mathrm{D}$, de acordo com a classificação do Instituto Brasileiro de Geografia e Estatística, IBGE, com base na renda familiar).

Em relação aos aspectos referentes ao conhecimento sobre as unidades de conservação, 53,53\% dos entrevistados não sabiam o significado de tal conceito, enquanto $46,47 \%$, sim.

Quando os entrevistados foram questionados se conheciam alguma unidade de conservação no município onde residiam, apenas 30,29\% disseram que sim, enquanto a maioria $(67,22 \%)$ respondeu negativamente.

Contraditoriamente às respostas das duas questões anteriores, observou-se que a maioria $(66,39 \%)$ dos entrevistados já tinha ouvido falar na APAE/CA. Entre eles, somente $45 \%$ já visitaram a unidade de conservação. E do total dos entrevistados, apenas $29,88 \%$ já visitaram o ativo ambiental em questão.

Quando os entrevistados foram perguntados se as atitudes deles poderiam influenciar de alguma maneira na qualidade ambiental da APAE/CA, 51,45\% responderam que sim.

No que tange às perguntas relacionadas à valoração ambiental, os resultados indicaram que $34,3 \%$ dos entrevistados estariam dispostos a contribuir financeiramente com algum valor para melhorar e preservar a qualidade ambiental da APAE/CA, ao passo que 57,12\% não. Dos entrevistados que não se dispuseram a pagar a quantia proposta, apenas 7,99\% demonstraram não se interessar pelos recursos naturais contidos na APAE/ CA. As causas da não contribuição deveram-se, principalmente, a motivos econômicos (30,27\%), seguidos pelos vieses de protesto por considerar o valor proposto alto $(20,58 \%)$ e já pagava muitos impostos $(17,92 \%)$.

\subsection{Estimativa do valor econômico para a APAE/CA}

A fim de obter as variáveis relacionadas à percepção ambiental a serem incorporadas no modelo (1), aplicou-se a análise fatorial. O número de fatores a serem retidos foi definido de acordo com o Critério de Kaiser, citado por Hair et al. (1998), obtendo-se, dessa forma, cinco fatores, os quais captaram 64,75\% da informação total contida nas 26 variáveis de percepção ambiental do formulário aplicado.

Para testar a adequabilidade dos dados à análise multivariada, utilizou-se o teste Kaiser-Meyer-Olkin (KMO), cujo valor 0,9201 mostrou que os dados utilizados apresentam excelente adequabilidade para a aplicação da análise fatorial.

Com o intuito de facilitar a interpretação das cargas fatoriais, rotacionaram-se os cinco fatores retidos utilizando o método Varimax no Stata 10, obtendo as seguintes interpretações desses fatores: 1) Fator 1 Importância das vertentes ambientais no cotidiano das pessoas: composto por seis variáveis que se relacionam positivamente com o mesmo, sendo responsável pela explicação de 38,46\% da variância total dos dados; 2) Fator 2 - Preservação e educação ambiental: composto por sete variáveis que se relacionam positivamente com o mesmo, sendo responsável pela explicação de 9,47\% da variância total dos dados; 3 ) Fator 3 - Relação entre a poluição e os prejuízos ao meio ambiente: composto por cinco variáveis que se relacionam positivamente com o mesmo, sendo responsável por $6,72 \%$ da variância total dos dados; 4) Fator 4 Responsabilidade para com o meio ambiente: composto por cinco variáveis que se relacionam positivamente com o mesmo, sendo responsável pela explicação de 5,78\% da variância total dos dados; e 5) Fator 5-Influência da sociedade sobre o meio ambiente: composto por duas variáveis que se relacionam positivamente com o mesmo, respondendo por $4,32 \%$ da explicação da variância total dos dados. 
Obtidas as variáveis de percepção ambiental, estimou-se o modelo (1) utilizando o Stata 10. Sobre a estimativa, ressalta-se que o software descarta os questionários que não apresentam todas as informações, ou seja, elimina-se a entrevista em que alguma das perguntas apresentadas no questionário não obteve resposta (o entrevistado não quis responder ou disse não saber a resposta). Dessa forma, utilizaram-se 366 questionários para estimação da DAP verdadeira.

Uma vez que o modelo apresentou seis variáveis estatisticamente significativas a pelo menos $5 \%$, a fim de aumentar a precisão da estimativa da DAP verdadeira buscada, optou-se por reestimá-lo somente com essas variáveis, sendo os resultados apresentados na Tabela 1 .

Sobre as qualidades estatísticas do modelo reduzido, o $\lambda$ calculado no teste da razão de verossimilhança, que é um teste de significância global do modelo, foi altamente significativo. Portanto, existe regressão entre a probabilidade de um indivíduo responder positivamente à valoração ambiental e as variáveis explicativas consideradas.

Quanto ao poder de previsão, observou-se que o modelo apresentou resultado satisfatório, posto que $70,38 \%$ de suas previsões estavam corretas. Se tomadas somente as previsões das respostas positivas à valoração contingencial, esse índice é de 64,60\%, e a proporção de acertos aumenta para $72,94 \%$, considerando apenas as respostas negativas.

Utilizando, então, o modelo reduzido e o método do bootstrapping, chegou-se a uma DAP verdadeira mensal mediana por pessoa de $\mathrm{R} \$ 15,43$. A escolha na distribuição obtida para a DAP verdadeira da mediana em vez da média deveu-se à obtenção de elevado desviopadrão em tal distribuição. Nessa situação, a utilização da mediana como medida de tendência central é mais indicada do que a média. Multiplicando, então, a DAP verdadeira mensal por 12 (número de meses de um ano) e pelo número de habitantes dos distritos considerados na amostra, o Valor Econômico do Recurso Ambiental (VERA) anual da APAE/CA percebido pelos habitantes da sub-bacia do rio das Velhas é de $\mathrm{R} \$ 10.398 .030,12$. Valor similar (R \$7.080.385,00) utilizando também o MVC foi encontrado por Adams et al. (2003), para o Parque Estadual Morro do Diabo.

\section{DISCUSSÕES}

Iniciando pela análise econômica dos coeficientes do modelo reduzido, verificou-se que o efeito marginal da variável DAPp sobre a probabilidade de o entrevistado aceitar contribuir é negativo, indicando relação de demanda. Tal efeito demonstra que aumento em uma unidade na DAPp, mantidas as demais variáveis constantes, diminui a probabilidade de pagamento em 0,76 ponto percentual.

O efeito marginal da variável renda familiar per capita, cuja média na amostra foi de $\mathrm{R} \$ 607,48$, indica que o aumento de uma unidade monetária na referida variável provoca elevação de 0,016 ponto percentual sobre a probabilidade de uma resposta afirmativa à valoração contingente. Considerando um aumento de

Tabela 1 - Resultados do modelo logit reduzido para estimação da DAP verdadeira para a APAE/CA.

Table 1 - Results of the reduced logit model to estimate true willingness-to-pay for APAE/CA.

\begin{tabular}{|c|c|c|c|c|c|}
\hline Variável & Coeficiente & Erro-padrão & Teste-z & valor-p & Efeito marginal \\
\hline DAPp & $-0,033262$ & 0,013486 & $-2,466439$ & 0,013600 & $-0,0076$ \\
\hline Renda per capita & 0,000685 & 0,000237 & 2,886214 & 0,003900 & 0,00016 \\
\hline Idade & $-0,023579$ & 0,007903 & $-2,983557$ & 0,002800 & $-0,0054$ \\
\hline C3 (1) & 1,007978 & 0,275844 & 3,654167 & 0,000300 & 0,2179 \\
\hline C5 (2) & 1,090811 & 0,273059 & 3,994778 & 0,000100 & 0,2366 \\
\hline Fator 4 (3) & 0,223996 & 0,133431 & 1,678739 & 0,093200 & 0,0515 \\
\hline Constante & $-0,961665$ & 0,416618 & $-2,308266$ & 0,021000 & - \\
\hline
\end{tabular}

Teste da razão de verossimilhança: $\lambda=2$ (FVLI - FVLR)

$\lambda=74,74$

Probabilidade média: $22,89 \%$

Obs. $\operatorname{com}(\mathrm{Y}=1)=142$ Obs. Com $(\mathrm{Y}=0)=226$ Previsões corretas $70,38 \%$

Fonte: Resultados da pesquisa

Notas: (1) variável dummy assumindo o valor 1 quando o indivíduo já tinha ouvido falar da APAE/CA e zero, caso contrário.(2) variável dummy assumindo o valor 1 quando o entrevistado concordava que suas atitudes poderiam influenciar de alguma maneira a APAE/CA e zero, caso contrário. (3) variável de percepção ambiental obtida a partir da análise fatorial, sendo denominada de "Responsabilidade para com o meio ambiente". 
$\mathrm{R} \$ 1.000,00$ na renda familiar per capita, a elevação sobre a probabilidade considerada seria de 16,00 pontos percentuais, indicando que essa variável tem influência importante para a valoração em estudo. Dessa forma, pode-se classificar a preservação da APAE/CA, de acordo com a teoria econômica, como um bem normal para os entrevistados, ou seja, quanto maior a renda, maior a demanda e, consequentemente, a disposição a pagar por tal preservação (VARIAN, 2012). Tal resultado vai ao encontro do fato de que, à medida que a renda aumenta, as pessoas têm maiores condições para atender às suas necessidades básicas e materiais e, por isso, passam a almejar maior nível de bem-estar, através de melhorias ambientais que possam aumentar a sua qualidade de vida. Resultados similares foram encontrados por Silva e Lima (2004) e Cirino e Lima (2008).

Em relação à idade, teve-se um efeito marginal negativo, embora pequeno, indicando que a elevação em um ano de vida do entrevistado reduz a probabilidade de pagamento em 0,54 ponto percentual. Em parte, esse resultado pode indicar que, com o passar do tempo, o indivíduo diminui seu interesse pelo ativo ambiental (APA), já que, em tese, conforme destacaram Mitchell e Carson (1989), terá menos tempo de vida para usufruir de suas benesses ou serviços ambientais. Mattos et al. (2007) também encontraram resultado semelhante ao valorar Áreas de Proteção Permanentes (APPs) da microbacia do Ribeirão São Bartolomeu, no Município de Viçosa (MG), sendo o valor encontrado de 0,38 ponto porcentual. O resultado deste estudo está em consonância com as possibilidades de negatividade do efeito idade levantadas teoricamente por Mitchell e Carson (1989) e empiricamente por Mattos et al. (2007) e Cirino e Lima (2008).

Quanto ao efeito marginal da variável dummy referente à questão se o indivíduo já tinha ouvido falar na APAE/CA, observou-se que respostas positivas a essa pergunta aumentam a probabilidade de pagamento em 21,79 pontos percentuais. Tal resultado revela que o fato de o indivíduo possuir vaga noção sobre a importância do patrimônio natural do ativo em questão tem forte influência sobre as chances de obtenção de uma contribuição positiva.

O efeito marginal da variável dummy referente ao fato de o entrevistado possuir consciência prévia de que as suas atitudes podem influenciar de alguma maneira a APAE/CA faz que, em média, a probabilidade de pagamento se eleve 23,66 pontos percentuais. Nesse sentido, observa-se que, quando o indivíduo percebe que o seu comportamento afeta a qualidade ambiental do patrimônio natural abordado neste estudo, há mais chances de contribuição positiva. Isso porque, quando o agente reconhece que seus atos podem, de alguma forma, degradar o ativo ambiental, ele tende a se tornar mais sensível a colaborar com a preservação através do pagamento de determinada quantia para esse fim.

No que tange às variáveis de percepção ambiental, relacionadas diretamente com esse último resultado, apenas o Fator 4 (Responsabilidade para com o meio ambiente) foi estatisticamente significativo, sendo o seu efeito marginal sobre a probabilidade de pagamento de 5,15 pontos percentuais. Nesse sentido, quando o entrevistado reconhece que a sociedade como um todo, incluindo ele mesmo, é responsável pela preservação da APAE/CA, há mais chances de pagamento positivo pela preservação do ativo em questão.

Em relação às variáveis que não se mostraram estatisticamente significativas no modelo completo, não é possível fazer inferências acerca de seus efeitos marginais, já que são elevadas as probabilidades de seus parâmetros estimados usados no cálculo do referido efeito serem zero. Alguns aspectos referentes à não significância de algumas dessas variáveis merecem ser destacados.

Quanto às dummies referentes aos distritos, observa-se que as suas não significâncias indicaram que o fator distrito não influencia estatisticamente na decisão de um entrevistado qualquer em aceitar o pagamento de determinada DAP proposta. Dessa forma, pode-se estimar uma única DAP verdadeira mediana por pessoa para os oito distritos nos quais a APAE/ CA se localiza.

Em relação à escolaridade dos indivíduos, essa também não se mostrou estatisticamente significativa para o pagamento. Tal fato contraria o esperado, ou seja, o grau de instrução influenciando positivamente a probabilidade de uma resposta positiva à valoração ambiental. Esse mesmo resultado foi encontrado por Silva e Lima (2004) e Cirino e Lima (2008) em outras unidades de conservação. Neste estudo, essa situação pode ser explicada pelo fato de que, independentemente do nível de instrução do entrevistado, percebeu-se, de maneira geral, através de questões do relacionamento APAE/CA - população e da percepção ambiental, preocupação e disposição na conservação do ativo em estudo. 
Retomando o VERA do ativo ambiental em estudo, é importante destacar que, segundo dados da Fundação João Pinheiro de 2008 disponíveis em The Nature Conservancy (2012), houve um repasse mínimo de ICMS ecológico para o Município de Ouro Preto pela manutenção da área da APAE/CA na cidade, no valor de R\$3.451,44/ano. No caso, tal repasse referente a essa última se faz também pela Floresta Uaimií, que é uma Unidade de Conservação incluída na APAE/CA ( $\mathrm{R} \$ 19.817,77$ anual para a Floresta). Uma vez que somando esses dois valores tem-se um montante bem inferior ao VERA encontrado neste estudo, torna-se evidente a importância de se repensarem as políticas públicas atuais referentes aos investimentos financeiros para a conservação da APAE/CA.

Ainda sobre o VERA estimado para a APAE/CA, ressalta-se que ele reúne os valores de uso, opção e da própria existência do ativo ambiental. Isso porque, mesmo considerando que os entrevistados usufruem de alguma maneira dos benefícios fornecidos pela APAE/CA, ainda assim o mercado hipotético construído não impede que os entrevistados revelem também as suas preferências em relação aos valores de não uso. Dessa maneira, o valor estimado ( $\mathrm{R} \$ 10.398 .030,12)$ pode ser interpretado como o valor total dos benefícios gerados pelo ativo em estudo e apropriados pela sociedade na área de interesse considerada neste trabalho. Destaca-se que, como se pretende com o valor encontrado gerar subsídios para a implementação concreta de políticas públicas e projetos voltados para a conservação e melhoria da APAE/CA, não houve preocupação em estimar VERA que abrangesse valores de existência para pessoas que residem fora na área de influência compreendida pelo recurso natural avaliado.

\section{CONCLUSÕES}

Este trabalho quantificou e analisou a DAP e o VERA pela manutenção e conservação da APAE/CA.

A escolha da disposição a pagar ou não foi influenciada pelas seguintes variáveis: DAP proposta no processo de valoração, renda familiar per capita, idade, se o indivíduo já ouviu falar ou não na APAE/ $\mathrm{CA}$, se as atitudes do entrevistado podem influenciar de alguma maneira o ativo em estudo e a variável de percepção ambiental "responsabilidade para com o meio ambiente". Em relação a esta última, destaca-se aspecto pouco explorado na literatura ao relacionar uma variável de percepção ambiental com a valoração econômica de um ativo natural. Para a APAE/CA, concluise que maior percepção ambiental dos entrevistados influencia positivamente na probabilidade de pagamento de uma taxa pública para a preservação do recurso natural em estudo.

Por meio da DAP estimada, chegou-se ao fluxo de benefícios anuais fornecidos pelo ativo em análise e percebidos e apropriados pela sociedade nela envolvida. O VERA encontrado foi significativo, já que se mostrou bastante superior ao ICMS Ecológico arrecadado para o Município de Ouro Preto, pela manutenção da área da APAE/CA na cidade. Dessa forma, a sociedade envolvida, ao se dispor a pagar um montante de recursos expressivos gerados a partir de uma taxa pública mensal destinada para a preservação da APAE/CA, dá indícios de que reivindica políticas governamentais efetivas de melhoria e conservação do ativo em questão.

\section{REFERÊNCIAS}

ADAMS, C. et al. Valoração econômica do Parque Estadual Morro do Diabo (SP). São Paulo: Páginas \& Letras, 2003.

BRUGNARO, C. Valuing riparian forests restoration: a CVM application in Corumbatai river basin. Revista de Economia e

Sociologia Rural, v.48, n.3, p.507-520, 2010.

CANTAGALLO, N. P.; KUWAHARA, M. Y. As possibilidades do ecoturismo em Parelheiros: percepção ambiental e disposição a pagar pela não degradação. Revista Jovens Pesquisadores, v.6, n.10, p.25-45, 2009.

CIRINO, J. F.; LIMA, J. E. Valoração contingente da Área de Proteção Ambiental (APA) São José MG: um estudo de caso. Revista de

Economia e Sociologia Rural, v.46, n.3, p.647-672, 2008.

HAIR, J. F. et al. Multivariate data analysis. 4.ed. New Jersey: Prentice Hall, 1998.

HANEMANN, M. W. Welfare evaluation contingent valuation experiments with discrete responses. American Journal of Agricultural Economics, v.66, n.3, p.332341, 1984.

Revista Árvore, Viçosa-MG, v.37, n.2, p.257-266, 2013 
HOFFMANN, R. Componentes principais e análise fatorial. Piracicaba: Escola Superior de Agricultura Luiz de Queiroz, 1999. 40p. (Série Didática, 90).

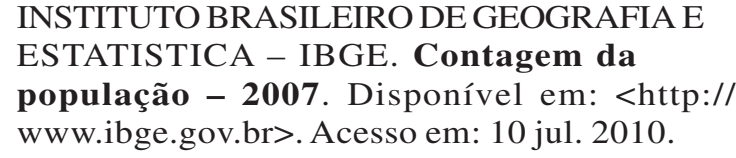

INSTITUTO ESTADUAL DE FLORESTAS/ UNIVERSIDADE FEDERAL DE VIÇOSA - IEF/UFV.

MATTOS, A. D. M. et al. Valoração ambiental de áreas de preservação permanente da microbacia do ribeirão São Bartolomeu no Município de Viçosa, MG. Revista Árvore, v.31, n.2, p.347-353, 2007.

MITCHELL, R. C.; CARSON, R. T. Using surveys to value public goods: the contingent valuation method. Washington: Resources for the Future, 1989.

MOTTA, R. S. Economia ambiental. Rio de Janeiro: FGV, 2006.

PACHECO, E.; SILVA, H. P. Compromissos epistemológicos do conceito de percepção ambiental. Rio de Janeiro: Departamento de Antropologia, Museu Nacional e Programa EICOS/UFRJ, 2007.

PEARCE, D. W. Economics values and the natural world. Washington: World Development Report, 1992.

REZENDE, R. A.; PRADO FILHO, J. F.; SOBREIRA, F. G. Análise temporal da flora nativa no entorno de unidades de conservação APA Cachoeira das Andorinhas e FLOE Uaimii, Ouro Preto, MG. Revista Árvore, v.35, n.3, p.435-443, 2011.
SCALCO, R. F. Desafios, paradoxos e complexidade na gestão do mosaico de unidades de conservação da área de proteção ambiental cachoeira das andorinhas - Ouro Preto/MG. 2009. 228f. Dissertação (Mestrado em Geografia) - Programa de Pós-graduação em Geografia, Universidade Federal de Minas Gerais, Belo Horizonte, 2009

SELLAR, C.; CHAVAS, J. P.; STOLL, J. R. Especification of the logit model: the case of valuation of non-market goods. Journal of Environmental Economics and Management, v.13, n.4, p.382-390, 1986.

SILVA, R. G.; LIMA, J. E. Valoração contingente do parque "Chico Mendes": uma aplicação probabilística do método referendum com bidding games. Revista de Economia e Sociologia Rural, v.42, n.4, p.685-708, 2004.

SILVEIRA, V. C. Valoração econômica e percepção ambiental da Área de Proteção Ambiental Estadual Cachoeira das Andorinhas - Sub-Bacia do Rio das Velhas-MG. 154f. Dissertação (Mestrado em Engenharia Ambiental) - Programa de Pósgraduação em Engenharia Ambiental, Universidade Federal de Ouro Preto, Ouro Preto, 2011.

SOUSA, G. B.; MOTA, J. A. Valoração econômica de áreas de recreação: o caso do Parque Metropolitano de Pituaçu, Salvador, BA. Economia, v.32, n.1, p.37-55, 2006.

\section{THE NATURE CONSERVANCY. ICMS}

Ecológico. Tabela de recursos do ICMS Ecológico gerados por unidade de conservação em 2008. Disponível em: <http:// www.icmsecologico.org.br/ index.php?option=com_content $\&$ view $=$ article $\& i d=72>$. Acesso em: 19 out. 2012.

VARIAN, H. Microeconomia: uma abordagem moderna. 8.ed. Rio de Janeiro: Campus, 2012.

WORLD COMMISSION ON ENVIRONMENTAL AND DEVELOPMENT - WCED. Our common future. Oxford: Oxford University Press, 1987. 